\title{
Augmentation of Understanding in Clinical Practise and Big Data Analytics
}

\author{
Peter C.M. van de Kerkhof \\ Department of Dermatology, Radboud University Medical Centre, Nijmegen, The Netherlands
}

In practise, how do we take the right decision for the individual patient if the evidence cannot be provided? The patient needs a good doctor who pays attention to triggering factors that are often hidden. He listens to the patient, examines the patient and discovers the things that are hidden. He then makes a diagnosis and provides personalised care and support. The good doctor is scientifically trained and permanently educated. He knows the important values but also the restrictions of the "evidence" of the treatments. The good doctor is "self-learning," constantly fed by his experiences with individual patients and capable of integrating these experiences. He is an empathic and systematic thinker. He instinctively knows how to get to the essence which lies buried under the multitude of triggering factors. He will offer his patient the care that is needed in his or her specific situation. Medicine is the art of patient care. Quoting Paul Klee: "Art does not reflect what is seen, rather it makes the hidden visible."

Deep learning is what physicians have been doing for years [1]: integrating knowledge and intuition. Deep learning has become crucial in a new world, the world of artificial intelligence.

We are witnessing great innovations in healthcare that allow for the multitude of factors that exist and influence the course of diseases. These factors can be classified un- der biological systems including genomics, epigenomics, transcriptomics and proteomics, under the medical system with data from the medical record and furthermore, and under welfare with a multitude of data regarding lifestyle, leisure activities, workload and health apps. Unfortunately, all these data are fragmented among electronic patient records that cannot talk to each other or are hidden due to privacy regulations. It is important that this information is stored in well-structured personalised clouds for each patient. Healthcare will make great progress as a result of "big data analytics," a digital process with "deep learning," exploring connections between a large number of triggering factors in very large patient populations. This development requires ethical reflection guaranteeing privacy on the one hand and enabling collective analyses on the other.

Relevant personal evidence will have to be provided for each patient on the basis of his or her individual characteristics. It concerns new evidence per patient with regard to multifactorial processes: personalised evidence in support of the good doctor. In the literature, this development is specified as "computational medicine," "precision medicine" and "P4 medicine: predictive, personalized, preventive, participatory" [2].

As the skin is, quite literally, right at the surface, dermatology in particular can play a leading role in this de-

\begin{tabular}{|c|c|}
\hline KARGER & $\begin{array}{l}\text { (c) } 2019 \text { The Author(s) } \\
\text { Published by S. Karger AG, Basel }\end{array}$ \\
\hline $\begin{array}{l}\text { E-Mail karger@karger.com } \\
\text { www.karger.com/drm }\end{array}$ & $\begin{array}{l}\text { This article is licensed under the Creative Commons Attribution- } \\
\text { NonCommercial-NoDerivatives } 4.0 \text { International License (CC BY- } \\
\text { NC-ND) (http://www.karger.com/Services/OpenAccessLicense). } \\
\text { Usage and distribution for commercial purposes as well as any dis- } \\
\text { tribution of modified material requires written permission. }\end{array}$ \\
\hline
\end{tabular}

Peter C.M. van de Kerkhof

Department of Dermatology, Radboud University Medical Centre P.O. Box 9101

NL-6500 HB Nijmegen (The Netherlands)

E-Mail P.vandeKerkhof@ derma.umcn.nl 
velopment. Skin imaging, subsequent pattern recognition by "machine-based learning" connected to systems biology, systems medicine and information on welfare in a digital environment will create a new form of evidencebased healthcare. On the one hand, the individual patient's cloud will contribute to data collection and, on the other, it will provide collective evidence for answers to relevant questions of the individual patient reconciling multiple factors.

Questions such as:

1 Is there a risk that this patient will develop severe symptoms of psoriasis?

2 Will this patient likely develop comorbidities and if so, which ones?

3 To what treatments can this patient be expected to respond well?

4 Is this a patient who requires active and early intervention to prevent cumulative damage to his or her health and welfare?

We are moving from reactive medicine towards proactive medicine.

\section{Key Message}

Psoriasis is a multifactorial disease. The estimation of the course of the disease and the selection of treatments is dependent on a host of factors. Big data are needed in order to be able to investigate the predictive value of the different aspects in an individual patient.

\section{Disclosure Statement}

P.C.M.K. received fees for consultancy service or lecturerships from Celgene, Centocor, Allmirall, Amgen, Pfizer, Philips, Abbott, Eli Lilly, Galderma, Novartis, Jansen Pharmaceutica, Leo Pharma, Sandoz, Bristol Mayer Squib, and Dermavant.

\section{References}

1 Kromenacker B, Marouf M, Shi VY. Augmented intelligence in dermatology: fantasy or future? Dermatology. 2019. doi: 10.1159/ 000497275 .

2 Flores M, Glusman G, Brogaard K, Price ND, Hood L. P4 medicine: how systems medicine will transform the healthcare sector and society. Per Med. 2013;10(6):565-76. 